\title{
Neonates Born to Mothers With Preeclampsia Exhibit Sex-Specific Alterations in Microvascular Function
}

\author{
MICHAEL J. STARK, VICKI L. CLIFTON, AND IAN M. R. WRIGHT
}

\begin{abstract}
Mother and Babies Research Centre [M.J.S., V.L.C., I.M.R.W.], University of Newcastle, Newcastle, New South Wales 2305, Australia;
\end{abstract} Neonatal Intensive Care Unit [I.M.R.W.], The John Hunter Children's Hospital, Newcastle, New South Wales 2310, Australia

\begin{abstract}
This study aimed to characterize early neonatal microvascular function after preeclamptic pregnancy with respect to infant sex and in utero growth. Peripheral microvascular blood flow was examined prospectively from 6 to $72 \mathrm{~h}$ of age using laser Doppler flowmetry in a cohort of term infants of normotensive women and women with late-onset preeclampsia. For male infants, those born to preeclamptic women had greater microvascular blood flow at $6 \mathrm{~h}(p<0.05)$ with no change over time. Male infants of normotensive women exhibited increasing blood flow with time ( $p=$ $0.005)$. Female infants of preeclamptic mothers exhibited similar blood flow at $6 \mathrm{~h}$ of age to females of normotensive mothers, followed by significantly greater blood flow by $72 \mathrm{~h}(p<0.001)$. Altered fetal microvascular structure and function in response to maternal preeclampsia may result in sexually dimorphic patterns of fetal growth and account for alterations in neonatal microvascular adaptation after birth. (Pediatr Res 65: 291-295, 2009)
\end{abstract}

$\mathrm{P}$ reeclampsia is a leading cause of morbidity and mortality in mothers and infants (1). It is currently believed to be a 2-stage disease (2) with shallow cytotrophoblast invasion of maternal spiral arterioles initially resulting in placental insufficiency. The subsequent release of soluble factors, such as endoglin and soluble fms-like tyrosine kinase 1 (3) into the feto-maternal circulation has been proposed to induce maternal systemic endothelial dysfunction and the clinical manifestations of the disease (4).

We have previously shown fetal sex-specific effects on maternal physiology and placental function in pregnancies complicated by inflammatory stressors $(5,6)$. With respect to preeclampsia, maternal endothelial dysfunction was greater in the presence of a male fetus (6). Similarly, male neonates demonstrate greater morbidity and mortality after preeclamptic pregnancy (7). Preeclampsia is known to be associated with adaptive changes in the fetal circulation and placentally derived factors implicated in the pathogenesis of the maternal manifestations of the disease are known to contribute to the development of neonatal thrombocytopenia and growth restriction (8). However, the influence of sex on endothelial dysfunction in neonates born to preeclamptic mothers has not previously been investigated.

Received March 28, 2008; accepted September 22, 2008.

Correspondence: Ian M. R. Wright, M.B.B.S., Kaleidoscope Neonatal Intensive Care Unit, John Hunter Children's Hospital, Newcastle, NSW 2310, Australia; e-mail: Ian.Wright@hnehealth.nsw.gov.au

Supported by Hunter Children's Research Foundation.
Neonatal endothelial dysfunction and abnormal regulation of vascular resistance may have a major role in cardiovascular instability in newborn infants (9) and disturbances of regional blood flow are known to play a crucial role in the pathogenesis of several significant neonatal morbidities $(10,11)$. The microcirculation of neonate is subject to considerable changes in the first days of extrauterine life (12) and is altered in response to mode of delivery (13), hypoxia (14), and ischemia (15). We have recently demonstrated that infants born prematurely exhibit sex-specific differences in microvascular blood flow and vasodilatory capacity (16). Males were found to exhibit microvascular dysregulation characterized by inappropriately low basal tone, and significantly, these differences were related to illness severity in the immediate newborn period (17).

In this study, we examined skin microvascular blood flow in term infants of normotensive and preeclamptic pregnancies. We hypothesized that, in light of the influence of fetal gender on maternal physiology in preeclamptic pregnancy and the sex-specific differences in microvascular blood flow after preterm birth, similar differences in neonatal microvascular adaptation would be observed after preeclampsia with males exhibiting dysregulated blood flow and inappropriate vasodilatation.

\section{MATERIALS AND METHODS}

Subjects. The study was approved by the human ethics committees of the University of Newcastle and The John Hunter Hospital, Newcastle, NSW, Australia. Pregnant women with a diagnosis of preeclampsia meeting the guidelines of the Australian Society for the Study of Hypertension in Pregnancy (18) and normotensive controls were recruited on presentation at the John Hunter Hospital as part of a prospective cohort study according to a previously described protocol (6). All the women in the preeclamptic group had both a systolic blood pressure of $>140 \mathrm{~mm} \mathrm{Hg}$ and/or diastolic blood pressure (Korotkoff $\mathrm{V}$ ) of $>90 \mathrm{~mm} \mathrm{Hg}$ arising after 20 wk gestation and proteinuria $>300 \mathrm{mg} / 24 \mathrm{~h}$ or spot urine protein/creatinine ratio $>30 \mathrm{mg}$ / mmol. Infants of preeclamptic mothers $(n=33)$ and control infants $(n=38)$ where studied at 6,24 , and $72 \mathrm{~h}$ of age. None of the preeclamptic subjects were defined as having severe preeclampsia. All mothers were aged between 18 and $40 \mathrm{y}$, had singleton pregnancies and were nonsmokers.

Factors that could have affected fetal-neonatal vascular development, such as maternal diabetes, essential hypertension, maternal smoking, neonatal asphyxia, chromosomal disorders, or congenital malformation excluded admission to this study. Women with preeclampsia may have received some or a combination of the following drugs: labetalol, hydralazine, and [alpha]methyldopa before delivery.

Vascular studies. Laser Doppler flowmetry assesses the function of blood vessels of the peripheral microvasculature of the skin (19). Low-intensity laser light is reflected from moving blood cells in the skin circulation, and a measurement of blood flow obtained. We used the Periflux 5001 Laser Doppler (Perimed AB, Järfälla, Sweden) with a single temperature-regulated probe sited on the lateral aspect of the lower limb. 
Experimental protocol. Investigations were performed with the infants in a thermo-neutral environment at least $1 \mathrm{~h}$ after the infant was last fed. Microcirculatory recordings were performed at times when the infant was lying supine, quietly, at 6,24 , and $72 \mathrm{~h}$ of age. The temperature regulated laser Doppler probe set at $34^{\circ} \mathrm{C}$ was placed on the lateral aspect of the calf, the same site being used for each recording, and microvascular blood flow allowed to normalize for $5 \mathrm{~min}$ after application of the probe before commencing the experimental protocol. Skin basal blood flow was then recorded for $5 \mathrm{~min}$ before standard provocations to allow for comparison between different studies and subjects, as previously described (20). After estimation of basal blood flow, lower limb blood flow was occluded using a standard sphygmomanometer to allow biologic zero for each experiment (20). Only recording areas free from movement artifacts were analyzed.

Statistical methods. Baseline microvascular blood flow did not demonstrate a normal distribution and was therefore log-transformed for all statistical analysis. The data are then described as mean \pm SEM. Data were analyzed using the Statistical Package for the Social Sciences (SPSS v14). Differences between groups were analyzed by multivariate analysis of covariance with post-hoc multiple $t$ tests using the Bonferroni correction to the $\alpha$ value. One-way analysis of variance was used for comparison of multiple data sets; $p \leq 0.05$ was considered significant.

\section{RESULTS}

The characteristics of the mothers and newborns are shown in Table 1. There were no significant differences in maternal age, gravidity, or parity between the groups. Although maternal body mass index was significantly higher in the preeclamptic group $(p<0.05)$, there was no difference in body mass index between those women who had a male infant and those who had a female. There was no significant difference in terms of proportion of small for gestational age infants, mode of delivery, proportion of male infants, or 5-min Apgar score between the groups. Male infants born to preeclamptic women had a significantly lower gestational age $(p<0.05)$. For infants born to preeclamptic mothers, there was no difference between the sexes with respect to antenatal exposure to antihypertensive therapies.

No significant relationship was demonstrated between baseline microvascular blood flow and gestational age $(p=0.18)$. In addition, mode of delivery did not significantly alter baseline microvascular flow at any time point $(\mathrm{F}=0.591, p=$ $0.556)$ for either group. A significant interaction was seen between time of microvascular assessment, neonatal sex, and maternal condition ( $\mathrm{F}=4.084, p=0.02)$. Post-hoc analysis showed that the male infants of preeclamptic mothers had no significant increase in blood flow over time. Male infants of normotensive mothers demonstrated a significant increase in baseline blood flow from 6 to $24 \mathrm{~h}(p=0.005)$, with no change from 24 to $72 \mathrm{~h}$ (Fig. 1). Post-hoc analysis showed that at $6 \mathrm{~h}$ of age those male infants of preeclamptic women had significantly higher baseline microvascular blood flow than those of normotensive women $(p<0.05)$. There was no significant difference in baseline microvascular blood flow between the male groups at 24 or $72 \mathrm{~h}$.

Female infants born to normotensive women showed no significant change in peripheral baseline microvascular blood flow with time. In the female infants born to preeclamptic mothers, there was a significant increase in baseline blood flow between 6 and $72 \mathrm{~h}(p<0.001)$ (Fig. 2). There was no significant difference between the preeclamptic and normotensive female groups at 6 or $24 \mathrm{~h}$, but a significantly greater baseline blood flow in the preeclamptic group at $72 \mathrm{~h}$ of age $(p<0.05)$. Removal of those women receiving antihypertensive treatment made no difference to the observed findings.

There was a significant interaction between the presence of preeclampsia and neonatal birth weight percentile $[\mathrm{F}(1: 185)=$ 7.5, $p=0.007$ ] (Fig. 3). Post-hoc comparisons demonstrated that female infants of preeclamptic mothers had significantly lower birth weight percentile than females of normotensive mothers $(28 \pm 4$ vs. $55 \pm 8, p<0.001)$. There was no significant difference between the preeclamptic and normotensive groups for birth weight percentile in the male infants. Although no significant difference was observed for birth weight between male and female infants of normotensive

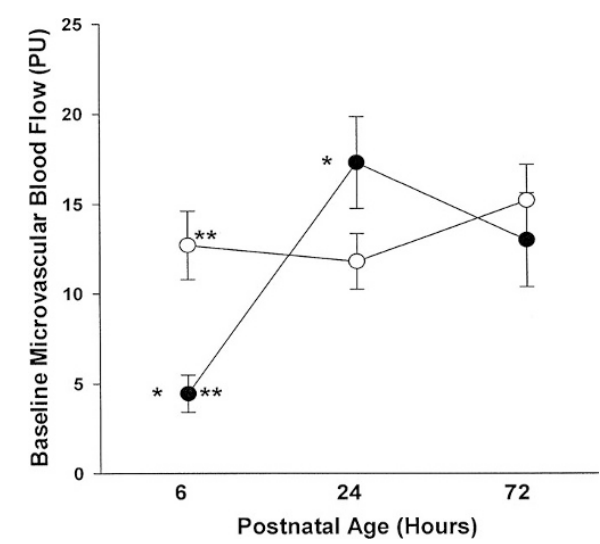

Figure 1. Baseline peripheral blood flow (PU) for male infants of normotensive $(n=21)(\bigcirc)$ and preeclamptic $(n=18)(\bigcirc)$ women studied at 6,24 , and $72 \mathrm{~h}$ postnatal age. ${ }^{*} p=0.0005$ ( $t$ test with Bonferroni correction), ${ }^{* *} p<0.05$ ( $t$ test with Bonferroni correction). All values are expressed as mean \pm SEM.

Table 1. Maternal and neonatal clinical characteristics

\begin{tabular}{|c|c|c|c|c|}
\hline & \multicolumn{2}{|c|}{ Normotensive } & \multicolumn{2}{|c|}{ Preeclamptic } \\
\hline & $\begin{array}{l}\text { Female infant } \\
\quad(n=17)\end{array}$ & $\begin{array}{l}\text { Male infant } \\
\quad(n=21)\end{array}$ & $\begin{array}{l}\text { Female infant } \\
\quad(n=15)\end{array}$ & $\begin{array}{l}\text { Male infant } \\
\quad(n=18)\end{array}$ \\
\hline Maternal age & $29(18-38)$ & $30(19-40)$ & $28.5(18-37)$ & $29(20-36)$ \\
\hline First trimester BMI & $26.4(24-31)$ & $25.9(23.1-30)$ & $27.5(24.6-38)$ & $28.7(24.8-39.9)$ \\
\hline Primigravidae & $10(59)$ & $7(33)$ & $9(60)$ & $10(55)$ \\
\hline Gestational age (wks) & $39(38-40)$ & $39(37-41)$ & $39(37-40)$ & $37(37-39)^{*}$ \\
\hline Vaginal delivery & $14(82)$ & $14(67)$ & $10(66)$ & $10(56)$ \\
\hline Five minute Apgar & $9(6-10)$ & $9(7-10)$ & $9(7-10)$ & $8(6-10)$ \\
\hline Small for gestational age & $1(6)$ & $3(14)$ & $2(13)$ & $2(11)$ \\
\hline
\end{tabular}

$* p<0.05$ ANOVA.

BMI, body mass index; ANOVA, analysis of variance. 


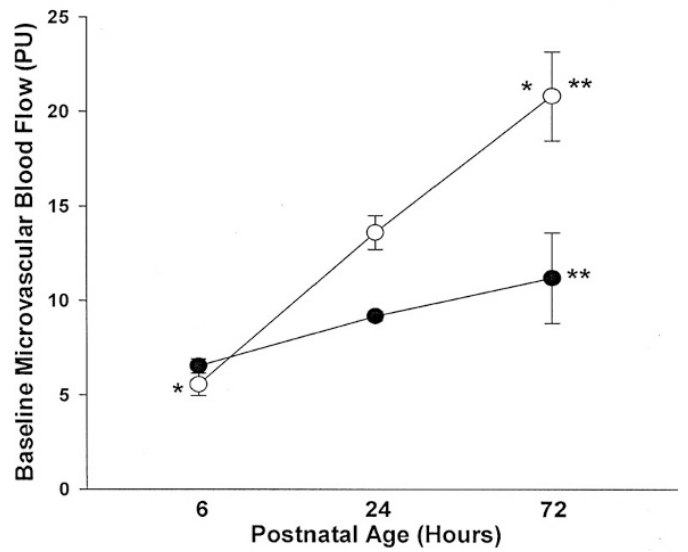

Figure 2. Baseline peripheral blood flow (PU) for female infants of normotensive $(n=17)(\bigcirc)$ and preeclamptic $(n=15)(\bigcirc)$ women studied at 6,24 , and $72 \mathrm{~h}$ postnatal age. ${ }^{*} p<0.001$ ( $t$ test with Bonferroni correction), $* * p<0.05$ ( $t$ test with Bonferroni correction). All values are expressed as mean \pm SEM.

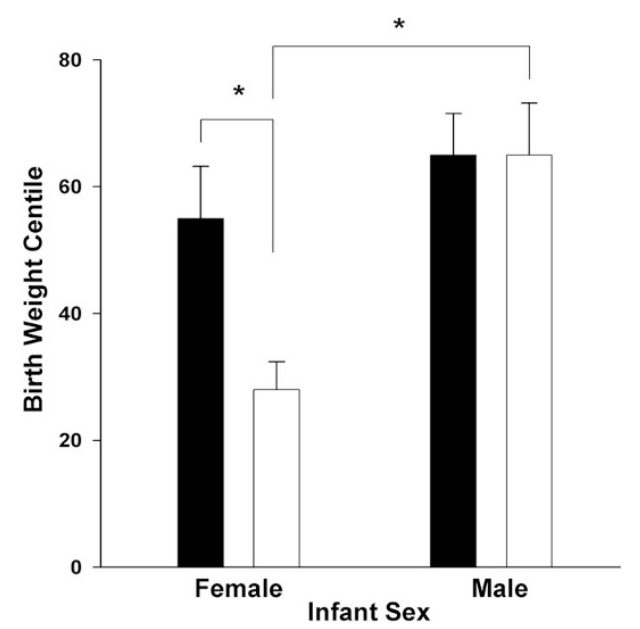

Figure 3. Birth weight centile for male and female infants of normotensive (घ) and preeclamptic ( $\square$ ) women on day 1 of life. The presence of PE was associated with decreased birth weight centile in female fetuses relative to the control population ${ }^{*} p<0.001$ (ANCOVA). A significant sex difference was observed in the PE group with females having decreased birth weight centile relative to males ${ }^{*} p<0.001$ (ANCOVA).

mothers, female infants were significantly smaller than males in the preeclamptic group ( $28 \pm 4 v s .65 \pm 8, p<0.001)$.

A significant interaction between maternal condition and neonatal head circumference percentile was observed $[\mathrm{F}(1: 185)=7.473, p=0.007]$ (Fig. 4). Infants of preeclamptic mothers exhibited significantly greater head circumference centile than those of normotensive mothers for both males $(66 \pm 5$ vs. $56 \pm 4)$ and females $(46 \pm 6 v s .36 \pm 4)$. A significant sex difference was also observed with male infants having greater head circumferences than females $[\mathrm{F}(1: 185)=$ $28.55, p<0.001]$ in both the normotensive and preeclamptic groups.

This is the first study to report sex-specific differences in the maturation of neonatal peripheral microvascular blood flow after pregnancies complicated by preeclampsia. Previously, we have reported significant sex-specific differences in basal microvascular blood flow and vasodilatory capacity in extremely preterm

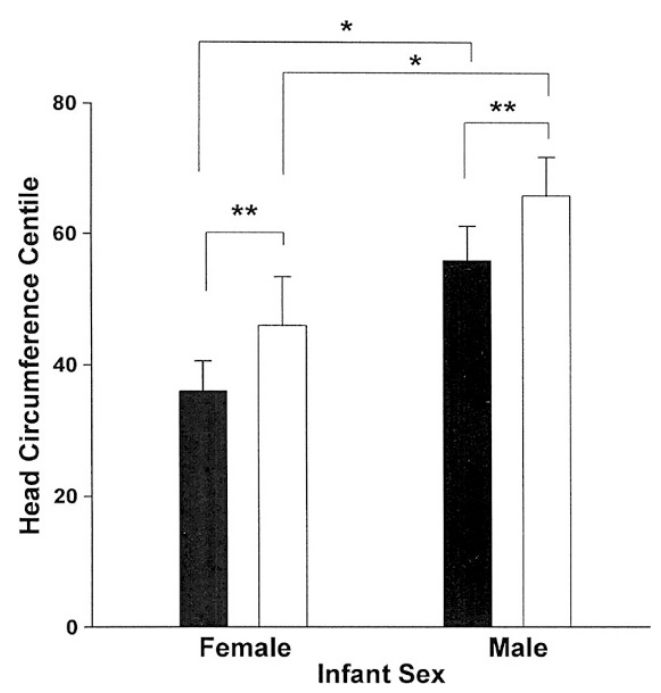

Figure 4. Head circumference centile for male and female infants of normotensive () and preeclamptic $(\bigcirc)$ women on day 1 of life. The presence of PE was associated with increased head circumference percentile in both male and female fetuses relative to the control population $* p=$ 0.007 (ANCOVA). A significant sex difference was observed in both groups with male infants having greater head circumferences than females $* p<0.001$, ANCOVA.

infants (16). Sexually dimorphic patterns of microvascular adaptation have not, however, been reported at term nor been shown to be influenced by maternal preeclampsia.

Previous studies of neonatal microvascular adaptation have reported significant changes both with gestational and postnatal age. Gestational age has been described to have a variable influence on microvascular function with blood flow reported to decrease $(21,22)$, increase $(15,23)$, and remain unchanged (24) with increasing gestational age. The current data demonstrates no relationship with gestational age, within a narrow range, but we have previously shown an inverse relationship over a greater span (17). Reports of temporal changes in neonatal peripheral cutaneous blood flow are similarly conflicting $(22,24)$. Although microvascular blood flow has been reported to remain unchanged over the first $24 \mathrm{~h}$ of life (13), other authors have described significant falls between days 1 and 7 (12,22). The current data demonstrates that in term neonates born after preeclamptic pregnancy, female infants exhibit similar baseline microvascular blood flow at $6 \mathrm{~h}$ of age to females of normotensive mothers followed by significantly greater microvascular blood flow at 24 and $72 \mathrm{~h}$. Conversely, male infants do not demonstrate a temporal change in blood flow in the presence of preeclampsia but were significantly more vasodilated than males of normotensive mothers at $6 \mathrm{~h}$ of age.

Sex-specific differences in temporal changes of microvascular blood flow where also observed in infants of normotensive women. Male infants exhibited a significant increase in blood flow from 6 to $24 \mathrm{~h}$ of age whereas female infants demonstrated no change with postnatal age. However, microvascular blood flow only exhibited a significant difference between male and female infants at $24 \mathrm{~h}$ of age. We have previously demonstrated a similar sexual dimorphism in preterm infants (16) at $24 \mathrm{~h}$ of age. Although the temporal nature 
of the sex-specific differences supports differences in vasoactive mediators and/or neural control as opposed to structural differences, the underlying mechanisms have not been fully elucidated and warrant further investigation. These findings highlight the importance of considering neonatal sex in the assessment of postnatal microvascular adaptation. Furthermore, the timing of any assessment may influence the observed effect.

Unexpectedly, there were sex-specific differences in the fetal growth response to maternal preeclampsia. The female fetus exhibits asymmetric growth with reduced birth weight whereas the male fetus maintains normal growth in the presence of preeclampsia. Data reporting changes in fetal and neonatal body proportion after abnormal pregnancy is limited although infants of preeclamptic mothers have previously been reported to have significantly increased head circumference to chest circumference ratio compared with infants born to normotensive mothers (25).

The differing temporal changes in microvascular blood flow and growth strategies demonstrated by male and female fetuses may be secondary to maternal microvascular adaptations in response to preeclampsia. We have previously examined maternal microvascular blood flow and vasodilatory capacity using laser Doppler flowmetry in pregnancies complicated by preeclampsia and demonstrated that fetal sex was associated with altered maternal vascular function (6). Specifically, maternal endothelial dysfunction, characterized by peripheral microvascular vasoconstriction, was greater in preeclamptic pregnancies with a male fetus. The normal growth of male neonates of preeclamptic pregnancies suggests that maternal adaptive increases in peripheral microvascular tone maintain fetal-placental blood flow despite maternal hypertension and placental insufficiency. This, in turn, leads to increased microvascular blood flow in the immediate postnatal period, which normalizes by $24 \mathrm{~h}$ of age.

In the female neonate, the progressive postnatal increase in microvascular blood flow may be a compensatory postnatal response to intrauterine redistribution of blood flow away from the peripheral circulation to the brain and major organs. We have shown in preeclamptic pregnancy that microvascular function in those women pregnant with a female fetus is not significantly different from the normotensive pregnant controls (6). These observations and the current data support a lack of compensatory peripheral vascular response to maternal hypertension, reduced uteroplacental blood flow and subsequent female fetal hemodynamic redistribution and alterations in female fetal growth and development (26).

In light of the prevailing hypothesis regarding the pathogenesis of preeclampsia focusing on an "ischemic model" with suboptimal uteroplacental perfusion and subsequent decreased fetal growth, the finding that male infants were appropriately grown may seem surprising. However, there is increasing evidence that babies born to mothers with preeclampsia at term have fetal growth similar to that of babies born to normotensive mothers $(27,28)$. These observations are in keeping with preeclampsia being a heterogeneous disorder (29). Interestingly both male and female fetuses of preeclamptic pregnancies had greater head circumference centile relative to neonates born to normotensive mothers. This may correspond with the theory that the underlying evolutionary reason for the persistence of preeclampsia is to sustain brain growth in the presence of placental restriction $(30,31)$.

Glucocorticoids may play a central role in conferring the sex-specific differences in placental function and fetal growth. Preeclampsia has been shown to be associated with a reduction in placental $11 \beta$-hydroxysteroid dehydrogenase 2 (32), a NAD-dependent unidirectional enzyme that oxidizes active cortisol to inactive cortisone (33). The decreased $11 \beta$ hydroxysteroid dehydrogenase 2 activity was accompanied by elevated umbilical cord cortisol and a decrease in fetal weight (34). Our previous studies support a sex-specific difference in the response of male and female fetuses to a rise in cortisol.

Glucocorticoids exhibit short-term vasodilator effects on the placental circulation (35) but long-term exposure may potentate vasoconstrictive responses. One potential pathway by which glucocorticoids may promote vasoconstriction is via the potent vasoconstrictor peptide endothelin-1. Preeclampsia is associated with elevated endothelin-1 in both the maternal (36) and fetal compartments (37) and glucocorticoids have been shown to potentate its vasoconstrictive actions. The female fetus appears to be sensitive to changes in glucocorticoid exposure and therefore may exhibit increased placental vasoconstriction (38) and uteroplacental insufficiency. The male placenta and fetus, conversely, is resistant to changes in glucocorticoid exposure (39) with the potential maintenance of uteroplacental blood flow, fetal growth, and development. Glucocorticoids may also alter fetal-placental vascular morphology. In the rat, dexamethasone administration inhibited vascular endothelial growth factor production and reduced placental angiogenesis in the late third trimester (40).

The influence of maternally administered antihypertensive agents on neonatal vascular function is a potential confounding variable in this study. The effect of antenatal antihypertensive exposure on neonatal microvascular adaptation after delivery has not previously been investigated. However, previous studies investigating neonatal adaptation after hypertensive pregnancy have demonstrated no differences in cardiovascular function, and in particular neonatal hypotension or rebound hypertension, in infants exposed to labetalol (41), hydralazine (42), or methyldopa (43) when compared with controls. In addition, there was no significant difference in the proportion of male and female infants of preeclamptic mothers exposed to each antihypertensive agent.

These sex-specific differences in microvascular flow may be a consequence of altered structural microvascular changes (microvascular density and microvascular compliance) in addition to differences in endothelial function with implications for future cardiovascular development (44). However, previous studies of microcirculatory density in neonates have failed to demonstrate altered microvascular structure despite marked differences in microvascular blood flow, with small sample size preventing investigation of sex-specific differences (45). Further studies should, therefore, examine potential sexspecific differences in maternal and neonatal microvascular structure and function in addition to the relationships between severity of maternal disease (including measures of circulating 
endoglin and soluble fms-like tyrosine kinase 1), uteroplacental blood flow, and fetal growth.

We have demonstrated for the first time sex-specific differences in neonatal microvascular blood flow after pregnancy complicated by preeclampsia. These sex-specific differences are evident in the immediate newborn period, a time of physiologic instability after birth. The significantly greater microvascular vasodilatation observed in male infants may impact upon the transitional circulation (17) and be a one factor contributing to the excess of morbidity associated with male sex after preeclamptic pregnancy. The underlying mechanisms resulting in this sexually dimorphic pattern of microvascular function have not been fully elucidated and warrant further investigation.

\section{REFERENCES}

1. Sibai BM, Caritis S, Hauth J 2003 What have we learned about pre-eclampsia? Semin Perinatol 27:239-246

2. Roberts JM, Cooper DW 2001 Pathogenesis and genetics of pre-eclampsia. Lancet 357:53-56

3. Levine RJ, Lam C, Qian C, Yu KF, Maynard SE, Sachs BP, Sibai BM, Epstein FH, Romero R, Thadhani R, Karumanchi SA 2006 Soluble endoglin and other circulating antiangiogenic factors in pre-eclampsia. N Engl J Med 355:992-1005

4. Levine RJ, Karumanchi SA 2005 Circulating angiogenic factors in pre-eclampsia. Clin Obstet Gynecol 48:372-386

5. Clifton VL, Murphy VE 2004 Maternal asthma as a model for examining fetal sex-specific effects on maternal physiology and placental mechanisms that regulate human fetal growth. Placenta 25:S45-S52

6. Stark MJ, Dierkx L, Clifton VL, Wright IM 2006 Alterations in the maternal peripheral microvascular response in pregnancies complicated by pre-eclampsia and the impact of fetal sex. J Soc Gynecol Investig 13:573-578

7. Vatten LJ, Skjaerven R 2004 Offspring sex and pregnancy outcome by length of gestation. Early Hum Dev 76:47-54

8. Tsao PN, Wei SC, Su YN, Chou HC, Chen CY, Hsieh WS 2005 Excess soluble fms-like tyrosine kinase 1 and low platelet counts in premature neonates of preeclamptic mothers. Pediatrics 116:468-472

9. Seri I 2001 Circulatory support of the sick preterm infant. Semin Neonatol 6:85-95

10. Dammann O, Allred EN, Kuban KC, Van Marter LJ, Pagano M, Sanocka U, Leviton A 2002 Systemic hypotension and white-matter damage in preterm infants. Dev Med Child Neurol 44:82-90

11. Yanowitz TD, Yao AC, Pettigrew KD, Werner JC, Oh W, Stonestreet BS 1999 Postnatal hemodynamic changes in very-low-birthweight infants. J Appl Physiol $87: 370-380$

12. Suichies HE, Brouwer C, Aarnoudse JG, Jentink HW, de Mul FF, Greve J 1990 Skin blood flow changes, measured by laser Doppler flowmetry, in the first week after birth. Early Hum Dev 23:1-8

13. Martin H, Norman M 1997 Skin microcirculation before and after local warming in infants delivered vaginally or by caesarean section. Acta Paediatr 86:261-267

14. Celander O 1966 Studies of peripheral circulation. In: Cassels D (ed) The Heart and Circulation in the Newborn and Infant. Grune \& Stratton, New York, pp 98-110

15. Celander O, Marild K 1962 Reactive hyperemia in the foot and calf of the newborn infant. Acta Paediatr 51:544-552

16. Stark MJ, Clifton VL, Wright IM 2008 Sex-specific differences in peripheral microvascular blood flow in preterm infants. Pediatr Res 63:415-419

17. Stark MJ, Clifton VL, Wright IM 2008 Microvascular flow, clinical illness severity and cardiovascular function in the preterm infant. Arch Dis Child Fetal Neonatal Ed 93:F271-F274

18. Brown MA, Hague WM, Higgins J, Lowe S, McCowan L, Oats J, Peek MJ, Rowan JA, Walters BN 2000 Australasian Society of the Study of Hypertension in Pregnancy. The detection, investigation, and management of hypertension in pregnancy: full consensus statement. Aust N Z J Obstet Gynaecol 40:139-155
19. Kubli S, Waeber B, Dalle-Ave A, Feihl F 2000 Reproducibility of laser Doppler imaging of skin blood flow as a tool to assess endothelial function. J Cardiovasc Pharmacol 36:640-648

20. Hu J, Norman M, Wallensteen M, Gennser G 1998 Increased large arterial stiffness and impaired acetylcholine induced skin vasodilatation in women with previous gestational diabetes mellitus. Br J Obstet Gynaecol 105:1279-1287

21. Beinder E, Trojan A, Bucher HU, Huch A, Huch R 1994 Control of skin blood flow in pre- and full-term infants. Biol Neonate 65:7-15

22. Wu PY, Wong WH, Guerra G 1980 Peripheral blood flow in the neonate. Changes in total, skin, and muscle blood flow with gestational and postnatal age. Pediatr Res 14:1374-1378

23. Riley ID 1954 Hand and forearm blood flow in full term and premature infants. Clin Sci 13:317-320

24. Beaufort-Krol GC, Suichies HE, Aarnoudse JG, Okken A, Jentink HW, Greve J 1989 Postocclusive reactive hyperaemia of cutaneous blood flow in premature newborn infants. Acta Paediatr Scand Suppl 360:20-25

25. Ounsted M, Moar VA, Scott A 1986 Proportionality of small for gestational age babies at birth: perinatal associations and post-natal sequelae. Early Hum Dev $14: 77-88$

26. Vyas S, Nicolaides KH, Bower S, Campbell S 1990 Middle cerebral artery flow velocity waveforms in fetal hypoxaemia. Br J Obstet Gynaecol 97:797-803

27. Jacquemyn Y, Osmanovic F, Martens G 2006 Pre-eclampsia and birthweight by gestational age in singleton pregnancies in Flanders, Belgium: a prospective study. Clin Exp Obstet Gynecol 33:96-98

28. Xiong X, Demianczuk N, Saunders LD 2002 Impact of pre-eclampsia and gestational hypertension on birth weight by gestational age. Am J Epidemiol 155:203-209

29. Ness RB, Roberts JM 1996 Heterogeneous causes constituting the single syndrome of pre-eclampsia: a hypothesis and its implications. Am J Obstet Gynecol 175:13651370

30. Chaline J 2003 Increased cranial capacity in hominid evolution and preeclampsia. J Reprod Immunol 59:137-152

31. Rockwell LC, Vargas E, Moore LG 2003 Human physiological adaptation to pregnancy: inter- and intra-specific perspectives. Am J Hum Biol 15:330-341

32. Schoof E, Girstl M, Frobenius W, Kirschbaum M, Dorr HG, Rasher W, Dotsch J 2001 Decreased gene expression of 11 beta-hydroxysteroid dehydrogenase type 2 and 15-hydroxyprostaglandin dehydrogenase in human placenta of patients with pre-eclampsia. J Clin Endocrinol Metab 86:1313-1317

33. Albiston AL, Obeyesekere V, Smith R, Krozowski Z 1994 Cloning and tissue distribution of the human 11B-dehydrogenase component of the rat liver 11Bhydroxysteroid dehydrogenase complex. Mol Cell Endocrinol 105:R11-R17

34. McCalla CO, Nacharaju VL, Muneyyirci-Delale O 1998 Placental 11Bhydroxysteroid dehydrogenase activity in normotensive and pre-eclamptic pregnancies. Steroids 63:511-515

35. Clifton VL, Wallace EM, Smith R 2002 Short-term effects of glucocorticoids in the human fetal-placental circulation in vitro. J Clin Endocrinol Metab 87:2838-2842

36. Mastrogiannis DS, O'Brien WF, Krammer J 1991 Potential role of endothelin-1 in normal and hypertensive pregnancies. Am J Obstet Gynecol 165:1711-1716

37. Orbak Z, Energia VM, Selimoglu MA 1998 Endothelin-1 levels in mothers with eclampsia-pre-eclampsia and their newborns. J Trop Pediatr 44:47-49

38. Walker BR, Connacher AA, Webb DJ, Edwards CR 1992 Glucocorticoids and blood pressure: a role for the cortisol/cortisone shuttle in the control of vascular tone in man. Clin Sci 83:171-178

39. Murphy VE, Gibson PG, Giles WB, Zakar T, Smith R, Bisits AM, Kessell CG, Clifton VL 2003 Maternal asthma is associated with reduced female fetal growth. Am J Respir Crit Care Med 168:1317-1323

40. Hewitt DP, Mark PJ, Waddell BJ 2006 Glucocorticoids prevent the normal increase in placental vascular endothelial growth factor expression and placental vascularity during late pregnancy in the rat. Endocrinology 147:5568-5574

41. Hjertberg R, Faxelius G, Lagercrantz H 1993 Neonatal adaptation in hypertensive pregnancy - a study of labetalol vs hydralazine. J Perinat Med 21:69-75

42. Gudmundsson S, Gennser G, Marsal K 1995 Effects of hydralazine on placental and renal circulation in pre-eclampsia. Acta Obstet Gynecol Scand 74:415-418

43. Henderson-Smart DJ, Horvath JS, Phippard A, Korda A, Child A, Duggan GG, Hall BM, Storey B, Tiller DJ 1984 Effect of anti-hypertensive drugs on neonatal blood pressure. Clin Exp Pharmacol Physiol 11:351-354

44. Vatten LJ, Romundstad PR, Holmen TL, Hsieh CC, Trichopoulos D, Stuver SO 2003 Intrauterine exposure to pre-eclampsia and adolescent blood pressure, body size, and age at menarche in female offspring. Obstet Gynecol 101:529-533

45. Goh KL, Shore AC, Quinn M, Tooke JE 2001 Impaired microvascular vasodilatory function in 3-month-old infants of low birth weight. Diabetes Care 24:1102-1107 